\title{
EL VESTIDO COMO SIGNO DE IDENTIDAD DE LA MUJER
}

\section{DRESS AS A SIGN OF FEMININE IDENTITY}

\author{
Rocío ARANA CABALLERO \\ UNIR (Universidad Internacional de la Rioja) \\ adaldrida77@gmail.com
}

RESUMEN El presente artículo estudia el vestido y el del maquillaje como código y signo de identidad, a través del teatro y la moda en el siglo XVII y en la actualidad. Se aplica el método histórico-lógico. Para el siglo XVII se analizan especialmente los ejemplos del "disfrazarse por amor" en la obra de teatro del autor Lope de Vega y "el disfrazarse para salvar honor" en la obra de Calderón de la Barca. En la segunda parte del artículo se aborda el maquillaje en el siglo XXI como signo y disfraz. Los resultados verifican diferencias y semejanzas entre ambas épocas y ambos códigos. La femineidad en los Siglos de Oro se plasmaba en el traje de la mujer que, para viajar, tomar las riendas de su vida, estudiar o salvar su honor debía vestir de hombre. La discusión se refiere a que los comportamientos socialmente permitidos para las mujeres se muestran así vinculados a su vestido y maquillaje.

Palabras clave: Disfraz masculino, Siglo de Oro, Calderón de la Barca, Lope de Vega, moda, maquillaje, teatro, vestido, feminidad, rol social, comportamiento.
ABSTRACT: This article examines dress and makeup as a code and as a sign of identity in theater and fashion in the seventeenth century and today. The study uses the historical and logical method. For the seventeenth century, we analyze examples of "dress for love" in the work of Lope de Vega and "dress to save honor" in the work of Calderon de la Barca. The second part of the article addresses makeup in the XXI century as a sign of and disguise of identity. The results verify the differences and similarities between the two periods and the two codes. Femininity in the Golden Age is embodied in the costume of the woman, who should dress as a man to travel, to take charge of her life, to study, or to save her honor. The discussion focuses on the fact that socially permissible behavior for a woman is strongly linked to her dress and makeup.

Key words: Male costume, sign, Golden Age, Calderón de la Barca, Lope de Vega, makeup, theater, dress, femininity, social role, behaviour. 


\section{Introducción: objetivos y metodología}

En el marco teórico de la moda como signo identitario femenino, este artículo pretende comparar, de forma muy sucinta, el valor y significado que en el Siglo de Oro español se le daba al vestido y el que se le otorga hoy, con especial incidencia en el maquillaje, auténtico "vestido" para la mirada y la tez de la mujer en la sociedad actual.

Así, su objetivo general es exponer, de manera breve, la idea de que en los personajes femeninos de las comedias y tragedias del siglo XVII español y a tono con las costumbres de la época, el vestido fue signo de identidad en su versión femenina y, necesario disfraz en su versión masculina que le permite asumir roles, impropios de una mujer según las convenciones, pero que le abrirán todo un mundo de posibilidades hasta entonces inédito. Tras la inevitable elipsis temporal, en la segunda parte del trabajo se observará cómo la moda y el maquillaje cumplen ambas funciones (femenino / masculino) en el siglo XXI. Ello implica deducir similitudes y diferencias entre los roles femeninos del siglo XVII y los muy versátiles de la actualidad.

En lo que respecta a la metodología, este trabajo se propone, en primer lugar, una somera revisión de la bibliografía específica sobre la moda, su sentido y funcionamiento desde el punto de vista de la identidad femenina. Y ello desde distintas ópticas: la filosofía de Simmel o Codina / Herreros; la sociología de Entwistle, Bordieu, o Squiacciarino; el psicoanálisis de Flügel, la lingüística y semiótica de Barthes (que también incursionó en la sociología), Eco, Lurie... o la ideología de género como instrumento de análisis en Soley-Beltrán (2015), amén de ciertos feminismos... Muchos de estos enfoques fueron absorvidos e incorporados en los estudios de Baudrillard, König o Lipovetsky, al tratar la moda (no sólo el vestido) como canal configurador de identidad. Imposible encorsetarse en un estudio teórico (no es el objetivo de este trabajo). El soporte teórico tiene como finalidad tomar herramientas de todos ellos y proyectarlas sobre dos parcelas puntuales (dada la brevedad del trabajo) de los siglos XVII y XX/ XXI. Con dos objetivos específicos:

- Analizar desde la teoría de la literatura y pormenorizadamente la función que ejerce el disfraz en el personaje de Rosaura, de La vida es sueño de Calderón de la Barca, y en Dinarda, de El anzuelo de Fenisa de Lope de Vega. Y evidenciar diferencias entre ambos códigos tras un somero análisis de los textos.

- Reflexionar (con instrumentos filosóficos y a la luz del mercado) sobre el papel que la sociedad actual otorga a la moda (vestido y maquillaje) femenina, "disfraz" que esconde o "vestido" que revela la identidad de la mujer.

El antiguo Diccionario de la moda de Rivière, ahora en nueva edición actualizada (2014), incluye una extensa entrada sobre el término moda, tomando como punto de partida las acepciones de la RAE: "se refiere al uso, modo o costumbre que está en boga durante algún tiempo, o en un determinado país, con especialidad en los trajes, telas y adornos. Entiéndese principalmente de los recién introducidos" (2014: 196). La moda es un fenómeno más amplio que el vestido, no en vano tanto el Diccionario de la RAE como el de Corominas la hacen arrancar del término latino modus, es decir, "modo" o "medida", "moderación, límite"... Aplicado a la indumentaria -dice Rivière"moda es aquel atuendo, estilo, prenda, color o complemento que se lleva por parte del grupo socialmente más importante o hegemónico, que es el capaz de influir en los demás" (2014: 196). Y añade: "El fenómeno de la moda ha sido analizado desde diversas perspectivas: las obras de Georg Simmel, Hebert Spencer, John Carl Flügel, René König, Thorstein Veblen, Gillo Dorfles, Roland Barthes o Jean Baudrillard como 
signo social o individual". Su enumeración parece el vaciado de uno de los libros más recientes y sistemáticos sobre este asunto, El imperio de la moda (2011), en que Inmaculada De la Puente Herrera pasa revista al fenómeno desde perspectivas históricas e ideológicas. Los cuatro capítulos en que se estructura atienden a otras tantas perspectivas de acercamiento: "la historia de la moda", la moda como integración y diferenciación social", "moda y comunicación" y "moda como configuración de la identidad". Asuntos muy entrelazados y que examinan varios de los intelectuales que se acercaron con interés al tema.

La moda ha sido considerada un retrato social, "la fotografía de cada momento histórico, un flash capaz de sintetizar toda una época, con su carga de aspiraciones, valores y contravalores" (Figueras, 2000: 165). Algo que filósofos como Simmel (Filosofía de la moda, 1907) ya habían adelantado en uno de los primeros análisis "filosóficos" de un fenómeno de todos los tiempos, que sufrirá una aceleración histórica sin par en la primera mitad del siglo XX). Y que ha seguido concitando miradas desde esta disciplina en el XXI: Mirando la moda, once reflexiones, coordinado por Codina y Herreros en 2004 es buen ejemplo de que el vestido, maquillaje, look... dice mucho de la identidad femenina y las tendencias sociológicas de cada momento, más allá de las conocidas manipulaciones de mercado. Hay un "lenguaje de la moda que Lurie ha estudiado concienzudamente (1994). Si bien los trabajos pioneros siguen siendo los de Barthes.

La evolución de la moda (vestidos, complementos, tendencias, estilos...) en el siglo XX habla de liberación y ruptura de códigos respecto a los estrechos cánones del Siglo de Oro español o la Inglaterra victoriana del XIX. Porque, al hablar de moda hablamos de "modelos de mujer". No en vano, la moda comporta identidad y valores -ha dicho Josefina Figueras, una de las estudiosas del asunto más prolíficas en el ámbito hispano: Protagonistas de la moda (2005), Moda y valores. El desafío de lo nuevo (2009), Moda española: una historia de sueños (2011), y Moda y estilos de vida: el poder de la novedad (2014) se apuntalan en tesis semejantes para radiografiar la moda española en las últimas décadas.

Años antes, la conocida periodista Lola Gavarrón en su ensayo La mística de la moda (1989), finalista del premio de ensayo Anagrama 1988, había mantenido tesis semejantes: "vestirse es todo un problema de identidad, de aceptarse y reconocerse tal y como se es" (1989: 14). El capítulo II de su ensayo habla mucho de moda y vestido como manifestación de poder, un lenguaje simbólico cargado de significado. Y ahí radica la cuestión: la evolución de la moda en el XX está estrechamente relacionada con las reivindicaciones igualitarias de las mujeres, su incorporación al trabajo profesional y su cruzada por una independencia económica y de todo tipo que las convierta en personas. Aunque paradójicamente y como demuestra Soley-Beltrán en ¡Divinas! Modelos, poder y mentiras (premio Anagrama de Ensayo 2015), en ese viaje sin retorno la mujer haya sido manipulada y obligada a adoptar provocadoras poses masculinas (el famoso smoking blanco y pelo corto de quien fue una reconocida top-model catalana hasta los 25 años y hoy es profesora de sociología en una de sus universidades). Y conviene recordar que cuando Ives Saint Laurent presentó su colección de 25 smoking femeninos con el consiguiente escándalo, tuvo buen cuidado de afirmar sus intenciones: "Nunca una mujer es capaz de aparecer más femenina -dijo- que cuando viste ropa que no está destinada para ella. Por contraste, su feminidad destaca más" (Figueras, 2009: 193). En el ensayo de Soley-Beltrán, se ha dado un paso adelante, a tono con la postmodernidad: su planteamiento siguiendo a Judith Butler, escapa a los denominados "esencialismos de la mujer" para plantear que el cuerpo humano ya no es masculino o femenino, sino un "constructo moldea- 
ble", con una identidad transversal. Porque la identidad no es tal, se ha convertido en una mera "percha para colgar los signos de la posible identidad" (Soley-Beltrán, 2015: 37).

La teoría va más allá que la práctica del mercado, aunque este permanezca atento a sus signos. Porque -como decía Coco Chanel-, "la moda no existe solamente en la ropa: está en el aire, la trae el viento, se la presiente, se la respira, está en el cielo y en las calles, nace de las ideas, de las costumbres, de las noticias"... En esta aventura, el vestido, como signo de femineidad, ha perfilado el rol femenino desde siempre. Aquí abordaremos su manifestación en el teatro barroco y en la actualidad.

En el siglo XVII, la mujer fue objeto de deseo del varón que regía su vida, una vida que pertenecía primero al padre y luego al esposo. El vestido desde esta óptica realzaba los atributos femeninos y la mujer se plegaba a las modas que fueron variando en aras de sus propósitos: sedas del Oriente, terciopelos de Castilla, encajes de Bruselas... recamados de oro y plata, perlas y piedras preciosas adornaron a las mujeres nobles durante siglos. Para comprobarlo, no hay sino disfrutar con el excelente libro de Avril Hart y Susan North, La moda de los siglos XVII y XVIII (2009), pormenorizado estudio de telas y costuras ("puntos, acolchado, encordonado; frunces, pliegues, drapeados, recogidos; cuellos, puños, bolsillos; botones; guarniciones; decoración aplicada; acuchillado, picado y grabado; puntos de aguja, encajes y calados; petos o petillos; guantes y zapatos" -según el índice). El estudio se hizo sobre la colección de vestidos históricos del Victoria \& Albert Museum, y las excelentes fotografías de Richard Davis y Leonie Davis dicen mucho más de la moda femenina entre 1600 y 1800 que cualquier estudio en sí mismo. "Los detalles nos dejan ver la impresionante mezcla de habilidad artesana y pensamiento creativo que culminó en los suntuosos y a menudo extravagantes atuendos de la sociedad pudiente, tanto por parte de hombres como de mujeres" (Hart, North, 2009: 9). Por supuesto, muchas de esas prendas se confeccionaron para fiestas y momentos estelares. Lo interesante del fenómeno es que "el uso de adornos costosos en los vestidos, incluyendo el hilo de oro y plata, nos ayuda a comprender la manera de ser, los gustos y los hábitos de sus dueños" (Hart, North, 2009: 9). Bordieu

El vestido era un arma de seducción y lo sigue siendo hoy: informal, estrafalario, sencillo o calculadamente posmoderno sigue adornando las no tan abundantes curvas femeninas al dictado de las mil y una modas. El estudio anterior incide en cómo el pasado da vida al presente: modistos como Lacroix, Lagerfeld o Galiano se inspiran hoy en este tipo de colecciones de museo que, por supuesto, se mantienen a nivel de la más alta sociedad.

No obstante y retornando a la historia, hubo un tiempo en que a la mujer vestida como tal le estaban vedadas múltiples actividades: la libertad de salir sola, estudiar en la universidad, escoger marido o lavar su honor mancillado por algún varón más o menos desaprensivo. Tanto el teatro de los Siglos de Oro como el cine actual sondearon esas posibilidades: Yentl (1983), protagonizada y dirigida por Barbra Streisand sobre un cuento del nobel judío Singer, incide en el deseo de educarse de una mujer cuya única vía para lograrlo radica en el uso del disfraz masculino.

En definitiva se trata de un tema de derechos y de identidad femenina, con registros muy variados desde el coqueteo frívolo o la persecución del amor, al replanteamiento de los objetivos vitales en las más inteligentes: ¿qué es ser mujer? ¿A qué aspira una mujer en cada etapa de la vida humana? Porque las funciones fueron variando: en tiempos pasados para conseguir una vida independiente y culta había que ser monja (Teresa de Jesús) o reina (Isabel la católica); o, en todo caso, librar astutas batallas 
potenciadas con subterfugios como la falsa modestia de Sor Juana Inés de la Cruz o los reclamos de amistad al posible amante (es el caso de Gertrudis Gómez de Avellaneda). ¿Acaso ellas no crearon máscaras autobiográficas, más allá del vestido o disfraz, para captar a sus partenaires masculinos? "Soy como consiga que me imaginéis"- titula Meri Torras su agudo libro sobre ambas (2003)-. Y no sin intencionalidad, Sonia Mattalía reúne una serie de estudios sobre la mujer bajo la rúbrica "Máscaras suele vestir" (2003).

Hoy la mujer en la sociedad occidental tiene un relativo margen de libertad, en términos de comparación con el Tercer Mundo. Ha conseguido ser ciudadana con voz y voto y ya no concibe su identidad sin el trabajo fuera del hogar (o, al menos, el derecho a ejercerlo). Aún así y más que nunca, tal vez por su mayor visibilidad social, le sigue gustando diseñar su identidad a través del vestido y el maquillaje. No necesita de la máscara del carnaval veneciano para sus deslices fuera de la norma, ni del traje masculino para acudir al trabajo, vengar sus ofensas o abrirse paso en la sociedad; pero le divierte adoptar distintas personalidades o sorprender y fascinar a su pareja con nuevos looks en un juego de máscaras según la ocasión. Aunque la primera y principal tenga que ver con un deseo de la humanidad desde la aurora de los tiempos: no envejecer. $Y$ en eso tienen mucho que decir moda y maquillaje, como ha recordado Seeling en su magnífico trabajo sobre Moda. El siglo de los diseñadores (1900-1999) (2000).

Por último: si para enterarse de ciertas estrategias y disfrutar con las "venganzas" femeninas, en los Siglos de Oro la multitud abarrotaba los corrales de comedias, hoy jóvenes y no tan jóvenes devoran blogs de belleza. Y la moda sigue sorprendiendo en pasarelas y centros comerciales con propuestas que "maquillan", "disfrazan" y manipulan también a una mujer que alcanzó un relativo grado de independencia en nuestras sociedades occidentales y sigue aún preguntándose por su identidad. No hay más que ver la proliferación de estudios femenino/ feministas...

\section{El disfraz en los Siglos de Oro: comedia/tragedia}

En este epígrafe se abordará el disfraz masculino en el teatro áureo. Debido a la amplitud del tema, muy bien trabajado por Bravo Villasante en La mujer vestida de hombre en el teatro español (1976) y Escalonilla en La dramaturgia del disfraz en Calderón (2004), el presente trabajo ha pretendido tan sólo comparar dos obras que lo utilizan. La clave para contraponerlas reside no solo en que sus autores sean Lope y Calderón, sino en el hecho de que son obras pertenecientes a dos géneros distintos (comedia/tragedia) y, por tanto, enfocarán el tema de manera diferente.

Al hablar del teatro áureo no es extraño que surja un tópico que viene de atrás y los hispanistas norteamericanos actualmente intentan desmontar. A lo largo de muchos años se ha identificado a Lope de Vega con un concepto de frescura, vivacidad, movimiento; y a Calderón de la Barca, por el contrario, con todo lo que implique rigidez, oscuridad y ortodoxia. Evidentemente hay diferencias entre los dos grandes dramaturgos del Siglo de Oro español. Las comedias de Calderón son más reflexivas que las de Lope ya que, en palabras de Parker, en ellas "la realidad" es modelada por medio de metáforas hasta convertirse en símbolo" (1991: 77). Pero además -continúa "-sus intrigas son más serias: siempre inteligentes, pero no siempre graciosas, y generalmente sin ningún tipo de frivolidad (...) las relaciones importan” (1991:184). 
Sea como fuere, ambos utilizan el disfraz. El hecho de que una mujer se disfrace de hombre en un escenario es algo que entusiasmaba al público del Siglo de Oro, como pone de manifiesto el mismo Lope en su Arte nuevo de hacer comedia:

Las damas no desdigan de su nombre;

y si mudaren traje, sea de modo

que pueda perdonarse, porque suele

el disfraz varonil agradar mucho. (Vega, 1973: 17)

Para defenderse de quienes sugerían prohibir las representaciones y para sostener sus ideas frente a toda una serie de academicistas que se oponen a su manera de hacer teatro, Lope se escuda en los gustos de su público. Como dramaturgo sabe muy bien lo que hace que una comedia funcione o no en el escenario, y defiende sus tesis aferrándose a esa sabiduría. Es evidente que el disfraz masculino constituye en esta época un guiño al público, que conlleva cierto escándalo. Pero para que este guiño resulte eficaz es imprescindible que no sea un elemento gratuito, un as que el dramaturgo "se saca de la manga" cuando prevé que la atención del público va a decaer. En resumen, que se inserte en una lógica argumentativa.

Porque lo importante cuando comienza el espectáculo no es que una dama salga al escenario con traje de hombre, sino la serie de confusiones y consecuencias grotescas que genera a lo largo de la representación. Más importante aún: ese disfraz tiene un porqué ( $y$ en su estudio Bravo Villasante señala más de trece posibles); una causa que al principio se desconoce y se va a ir desvelando durante su puesta en escena; lo que tendrá en vilo al público. Hay una historia detrás, un enigma por resolver y para lograr su meta el traje de hombre es el aliado femenino, convirtiéndose en una clave en el entramado de la obra.

En resumen: el disfraz masculino como signo, pero también como arma. Un arma en la mujer, en esa época atada de pies y manos por las convenciones sociales (y el teatro se hace eco de algunos casos reales que en ocasiones pasaron a la literatura, como La monja alférez, (1995), supuesta autobiografía de Doña Catalina de Erauso). Un arma incluso en manos del dramaturgo, que puede desorientarnos presentando un fin falso para luego sorprendemos con el verdadero. En una comedia, a su autor le es lícito jugar con el público, pero siempre manteniéndose dentro de la lógica argumentativa.

El anzuelo de Fenisa, (publicada en 1617), de Lope de Vega, es comedia de enredos y situaciones cómicas, y por ello el motivo del disfraz será liviano, al igual que el comportamiento de sus personajes. En un marco rufianesco y de moral relajada, tras la presentación al público de la cortesana Fenisa, aparece ante él Dinarda vestida de varón y acompañada de dos pajes que la creen hombre, conociéndola por el nombre de Dinardo, y serán los que participaren en su segunda transformación (o impostura), en Don Juan de Lara, noble caballero español:

Fab. Oid: echemos los tres

suertes quién será el señor,

y al que saliere, en rigor

sirvan los dos.

Din. Justo es.

Ber. Añadirémosle un don, diremos que es caballero, y aunque con poco dinero, tendrá mucha presunción. (Vega, 1998: 788-789) 
La impresión que causa este primer diálogo entre Dinarda, Fabio y Bernardo es esta: los tres son libres y más cercanos al mundo picaresco que al refinado de caballeros y damas. Llegan a Sicilia para ganarse la vida de un modo aventurero, quizás engatusando a alguna mujer rica. Entre los tres está Dinarda, que gana el sorteo y se hace dueño de los otros dos, bajo el nombre de Don Juan de Lara. Al principio ni Fabio ni Bernardo sospechan que su compañero de andanzas sea otra cosa que un hombre, aunque en algún momento de la obra surgen dudas, amparadas en la belleza femenina de su compañero. El motivo parece claro: Dinarda se disfraza de hombre para vivir mejor, con más seguridad y libertad, en ese mundillo de pícaros. Para poder ser dueño de los otros, dado su carácter fuerte, decidido y audaz, y para conseguir cuanto más dinero mejor por el método de enamorar damas, arte que domina según ella misma dice.

Planteado el engaño, el público espera un entretenimiento sin mayores sorpresas: amor, burlas, disfraces, promesas falsas y celos fundados e infundados. Lope ofrece al público una divertidísima comedia cuyo plato fuerte consiste en los embrollos que esta insólita situación va a generar: de un lado Fenisa, la rica cortesana que presume de esclavizar a todo hombre que la mire, -de ahí el título, su belleza es su mejor "anzuelo" para pescar enamorados-, y de permanecer inmune a los dardos del amor. Del otro Dinarda, bajo el nombre de Don Juan, que casi sin proponérselo la enamora locamente.

El momento del encuentro entre las dos protagonistas llega al final del acto primero de la comedia: la compañía de Osorio, antiguo amante de Fenisa e introductor de Don Juan en su círculo, aporta a Dinarda un halo de verosimilitud que acelera el enamoramiento de la cortesana. Ya en ese encuentro, Fenisa cae rendida ante la belleza de Don Juan de Lara, protagonizando un amor a primera vista que entronca con la idea petrarquista del amor, que es la que suele describir Lope de Vega en sus personajes: la belleza del ser amado es una flecha que hiere los ojos del amante; por eso, los personajes lopescos se enamoran a través de la vista. Sin embargo, en esta comedia el ideal petrarquista se resquebraja con ironía lírica, ya que los ojos engañan al amante, y las flechas con que hiere el amor no son solo dardos envenenados sino también dardos mentirosos.

Fen. (Escucha, Celia.)

Cel. (Ya escucho.)

Fen. (¡Notable español!)

Cel. (¡Gallardo!)

Fen. (En mi vida tuve amor, pero ya fuera mejor no haberle visto.)

Cel. (Eso aguardo.)

Fen. (De Sevilla dice que es.)

Cel. (Es gente en extremo airosa.) 
Fen. (Fuera de la cara hermosa, me matan piernas y pies [...]

que del hombre la hermosura

consiste en piernas y brío. (Vega, 1998: 803)

El disfraz masculino actúa en esta comedia, al modo de otras de Tirso (como Don Gil de las calzas verdes) y del mismo Lope, como un espejo que deforma la realidad multiplicándola, que hace soñar a sus protagonistas con quimeras. Sin embargo, vivir libremente y burlar damas ricas no podía ser el único objetivo del disfraz de Dinarda, ya que la obra carecería de interés más allá del espectáculo grotesco. Lope tenía la posibilidad de "engañar" al público, que por otra parte debía saber de antemano cómo suelen funcionar estas comedias de enredo, donde al final nada es lo que parece. Era previsible que Fenisa, después de alardear sobre su talento para enredar hombres, sin enredarse ella misma, acabara picando en el anzuelo equivocado. Lo que ya no era tan previsible dentro de la obra es que uno de los pretendientes de la cortesana, Albano, reconociera a Dinarda, relatando acto seguido sus pasados amores con ella y el trágico final que le obligó a huir de España.

En las comedias áureas no es extraño este tipo de enredos que relacionan a los personajes más dispares, al modo de una madeja de hilo que se va enredando, enredando... hasta que un último nudo lo desenreda todo de forma casi milagrosa. Los espectadores disfrutan con cada dificultad añadida... cada nueva confusión hace crecer el interés del público; es un mecanismo al servicio exclusivo del placer, porque la convención dicta que en una comedia nada grave puede ocurrir.

En El anzuelo de Fenisa, como sucede en la gran mayoría de comedias áureas, todos los enigmas se solucionan en el acto tercero, y el final llega de forma bastante rápida, lo que parece indicar que la clave de una comedia no radica en él. El público espera un final feliz, con boda incluida. Pero lo que hace cada comedia distinta, única e irrepetible, es el proceso, el modo en que los obstáculos se van acumulando primero y despejando más tarde. En ese proceso los elementos esenciales son la astucia, osadía y discreción con que actúan los personajes femeninos para lograr su empeño. Ellas saben perfectamente qué quieren y cómo lograrlo.

Aproximadamente a la mitad de este último acto, Dinarda desvela la verdadera intención de su disfraz, al quedarse sola y declamar un soneto de los que suele escribir Lope en estas ocasiones. Su "loco intento" surte el efecto esperado, ya que el increíble parecido de Don Juan con la antigua enamorada, y las sospechas de que se trata de ella, avivan en Albano un amor que creía ya muerto. Y al final Dinarda revelará su identidad verdadera, logrando las paces entre su hermano y su enamorado (cuya enemistad era el verdadero obstáculo de los amores entre Albano y ella), y consiguiendo la ansiada boda y la esperada venganza de la pícara Fenisa.

Calderón actúa de un modo muy diferente, porque distinto es el código en el que escribe. Resulta obvio el hecho de que el disfraz masculino poseerá un por qué radicalmente distinto en una tragedia que en una comedia: "Si el drama de honor trata del destino de los casados con sus problemas de honor y de celos de honor, la comedia de capa y espada trata del destino de los solteros con sus problemas de amor y de celos de amor"' (Valbuena Prat/Wardropper, 1983: 777).

La tragedia tiene un fin moralizador y un carácter grave del que la comedia carece. Esto constituye una convención, no tiene nada que ver con la ideología del dramaturgo. Al ir a ver una tragedia, el público espera sucesos graves y un final ejemplar, una 
catarsis, frente al asunto ligero, con muchas confusiones y liviandades que promete una comedia.

\section{Ilustración 1: La vida es sueño dirigida por Helena Pimenta}

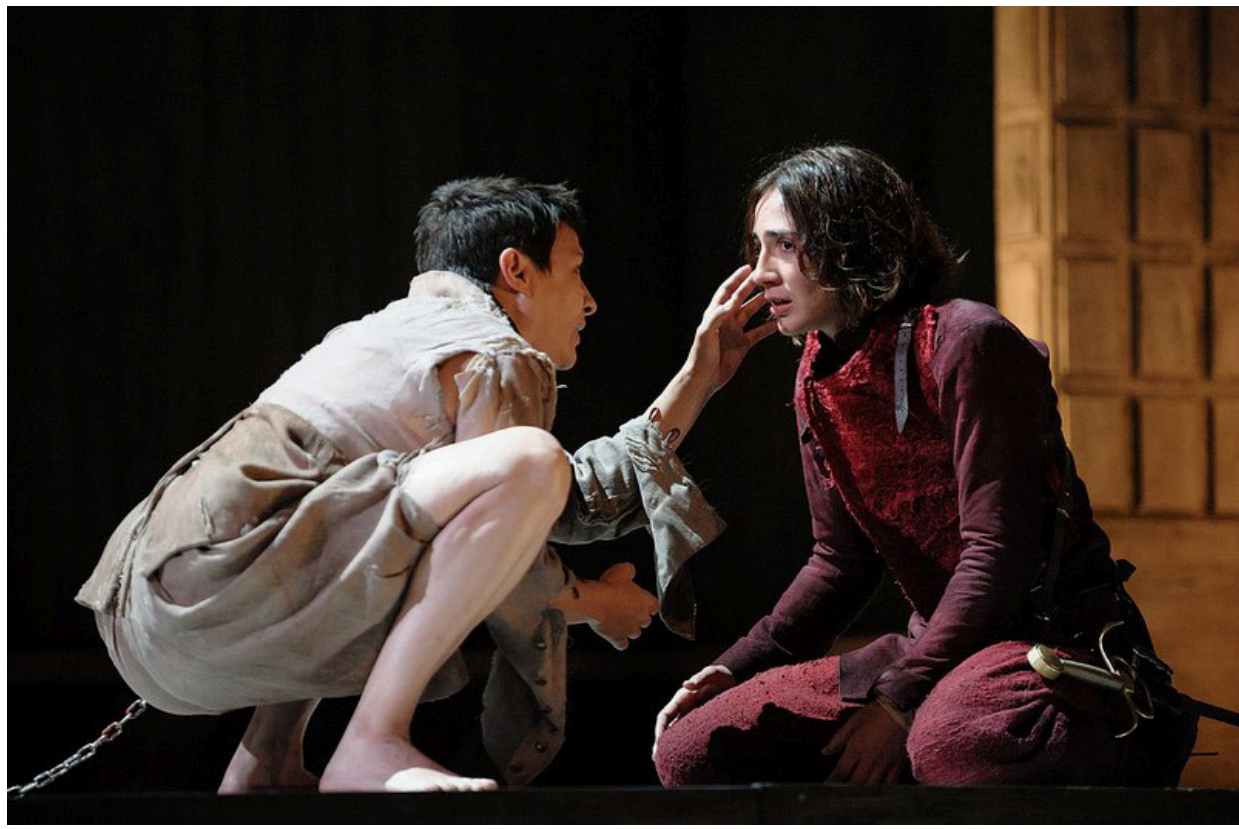

llustración 1: La vida es sueño dirigida por Helena Pimenta

(Fuente: http://www.palomamaria.com/

llega-a-madrid-\%E2\%80\%9Cla-vida-es-sueno\%E2\%80\%9D-con-marta-poveda/)

Los motivos que tiene Rosaura para vestirse de hombre en La vida es sueño (1635), de Calderón de la Barca, son diametralmente opuestos a los de la protagonista de El anzuelo de Fenisa. Dinarda aparecía como un personaje completamente metido en la acción, de carácter aventurero, poco reflexivo, práctico, ligero y chispeante, concentrado en planear su estrategia; y para conseguirla se vale del disfraz. Hasta muy avanzada la obra no sabemos lo que piensa o siente en realidad. En cambio Rosaura desde el principio es caracterizada como una mujer con hondura psicológica y filosófica, un personaje que esconde un secreto, que por supuesto aún no desvela al público y no duda en disertar sobre su triste situación ("Bien mi suerte lo dice; /más, ¿dónde halló piedad un infelice? (Calderón, 1997: 86).

Tras este monólogo que luego se convierte en diálogo con su criado Clarín y que sirve también para escenificar el tiempo que transcurre entre la bajada del monte y la llegada al palacio, se produce el primer encuentro entre la protagonista femenina y Segismundo. Surge en él una admiración por Rosaura que será clave en su proceso de conversión, según Ruano de la Haza:

Rosaura es esencial en el proceso del desarrollo intelectual de Segismundo, pues ella es la clave que le permite dar coherencia a lo que él creía una existencia fragmentada y desconcertante. (1994: 66) 
Rosaura es un enigma, una mujer que, como advierte Astolfo al final de la obra, "no sabe quién es". En ese sentido Rosaura es un espejo de Segismundo, por lo que este encuentro causa la admiración mutua en ambos. Es ésta una tesis defendida por numerosos hispanistas que beben del estudio de William Whitby:

Esto es lo que Segismundo infiere: su identidad. Y corriendo parejas con esta búsqueda de su propia identidad está la búsqueda de la personalidad de Rosaura.

“¿Quién eres", pregunta a Rosaura cuando primera vez se encuentran ambos en la prisión. (1996: 634)

Segismundo muestra su atracción por Rosaura justo después de que ella apelase a sus sentimientos de ser humano, lo que le hace contemplar detenidamente y con una calma inusitada al extraño que ha osado usurpar su terreno. Según Whitby, "Rosaura despierta en él el deseo de ver" (1996: 637). La belleza hiere esta vez los ojos del amante, pero también sus oídos, porque es la voz de Rosaura la que desata el interés de Segismundo, hasta arrancarle esta lírica y grandiosa declaración:

Con cada vez que te veo

nueva admiración me das,

y cuando te miro más,

aún más mirarte deseo.

Ojos hidrópicos creo

que mis ojos deben ser,

pues cuando es muerte el beber

beben más, y desta suerte,

viendo que el ver me da muerte,

estoy muriendo por ver. (Calderón, 1997: 94)

Ciriaco Morón Arroyo y Whitby ahondan en la visión platónica que subyace en este primer encuentro, y en el hecho de que Rosaura encuentre a Segismundo cuando aún está vestida con traje masculino; admiración que se transforma en deseo sexual en el segundo acto, cuando la contempla convertida ya en dama de la corte:

Es fácil percibir en el encuentro de Rosaura y Segismundo la visión platónica de la mujer. Rosaura tiene, sobre todo, el poder civilizador de la belleza. Segismundo no sabe todavía que Rosaura es mujer, pero no importa: la belleza masculina también domestica. La actitud contradictoria de Segismundo frente a Rosaura desde este primer encuentro hasta el último, ejemplifica la paradoja de la belleza platónica: "enciende el corazón y lo refrena. (Morón Arroyo, 1997: 19)

Durante todo este primer acto, Rosaura seguirá vestida de hombre, y no sólo su hábito será de varón. También su proceder y sus palabras lo serán. Así, en su primer monólogo se queja tras la caída con exclamaciones violentas. En esta presentación, Calderón muestra por medio del soliloquio el carácter decidido de su personaje femenino principal. Y, cuando Clotaldo le salva la vida, ella se le ofrece con estas palabras:

La vida, señor, me has dado,

y puesto a tu cuenta vivo, eternamente seré

esclavo tuyo. (Calderón, 1997: 118) 
A lo largo del primer y el segundo acto la trama se complica, al igual que sucedía en la comedia de Lope. Clotaldo, el guardián de Segismundo, reconoce en el hombre que ha apresado, -es decir, en Rosaura disfrazada-, a su propio hijo, al ver la espada que lleva. El mecanismo es el mismo que se utiliza en las comedias, pero se persigue un fin distinto: el cúmulo de enredos no provoca risa sino más dramatismo, pues este descubrimiento coloca a Clotaldo en una disyuntiva: tiene que entregar al prisionero, sabiendo que es su hijo. Es también en esta escena cuando Rosaura revela una parte del misterio, que explica su proceder:

\section{Vengo a Polonia a vengarme \\ de un agravio. (Calderón, 1997: 100)}

Clotaldo fuerza a su hija a decirle cuál es el agravio que desea vengar y la convence de que mude su disfraz masculino, y aparezca en el acto segundo como dama de la corte. Rosaura tiene carácter suficiente como para vengar su deshonra, pero es mujer. Y según el código del honor era un hombre, (marido, padre o hermano de la ultrajada), quien debía recuperar la honra perdida. Por eso es estrictamente necesario el disfraz. Dinarda se disfraza por amor, pero Rosaura se disfraza por honor. Como afirma Rosa Ana Escalonilla:

La justificación del paso del disfraz varonil a otro femenino se encuentra en el desarrollo mismo de la acción y en el cambio de actitud de Rosaura. Al principio era ella quien pretendía restaurar su honor por sí misma y para ello le era imprescindible un traje masculino. Más tarde, Clotaldo, como padre de la joven que es, aunque ella lo ignore, se ha ofrecido para ser quien vengue su honor. (2004: 34)

Y si en El anzuelo de Fenisa la acumulación de obstáculos generaba una súbita solución, en La vida es sueño el hecho de que Rosaura mude traje, abandonando su disfraz varonil, posibilitará un sutil cambio de estilo en la obra durante el acto segundo, en el que, paralelamente a la trama principal centrada en Segismundo, vemos actuar a Astolfo como enamorado de Estrella, a Estrella celosa de un antiguo amor y a Rosaura enamorada aún del hombre que la ha ofendido.

Pero, tras la escena de celos que sirve para enterar al público de los sentimientos amorosos de Rosaura, se esconden intenciones más profundas. Ha sido el abandono de Astolfo y la ausencia de un padre lo que motivó a la heroína a emprender un viaje disfrazada. Y más allá del deseo de venganza o nueva conquista, Rosaura está luchando, como ya hemos dicho, por conseguir una verdadera identidad. En palabras de Ruano,

La intriga amorosa sirve simplemente de recurso convencional que suministra a Rosaura una razón plausible para vestirse de hombre e ir a Polonia en busca de su padre, la única persona que le puede ayudar a recuperar su nombre-es decir, su identidad social- sin la cual no podría casarse con Astolfo al final. (1994: 59)

En el tercer acto, Rosaura aparece nuevamente ante los ojos de Segismundo, vestida de mujer pero adornada con armas de varón. Acude a pedir pero también a ofrecer, una actitud apropiada en una mujer independiente y completa, pero aún así herida en su honor. La francesa Michélle Gendreau Massaloux compara en su estudio sobre Rosaura (1983) el proceder de ésta con respecto a otras heroínas de la literatura clásica. En su ensayo se centra en este último acto, en el que Rosaura 
muestra claramente su ser híbrido y complejo. Sufre a lo largo de la obra una mutación, una evolución tan compleja como la que se opera en Segismundo y paralela o incluso correlativa a ella: en el primer acto la vemos vestida de hombre; en el segundo, vestida de mujer, pero es en el tercero cuando Calderón nos descubre la complejidad y fortaleza de Rosaura, atribuyéndole rasgos femeninos y masculinos a un mismo tiempo: de ahí la modernidad de esta obra y la profundidad ontológica e incluso metafísica del uso del disfraz.

Los personajes femeninos de las dos obras estudiadas no pueden ser más distintos, aunque tengan en común el disfraz masculino. El lenguaje libre y bullicioso que utiliza Dinarda (¡Bueno va!, Picada está ya/ aunque fue sin alfiler), se contrapone al lenguaje reflexivo que caracteriza a Rosaura (más, ¿dónde halló piedad un infelice?)

Dinarda confiesa perseguir un "loco pensamiento", que causó su viaje. El de Rosaura posee una honda razón. El amor inspira la forma de actuar de ambas, pero en el caso de la segunda es un amor agraviado y combinado con matices filosóficos, ya que la consecución de ese amor le urge a la búsqueda de su identidad. Una búsqueda ontológica que en el teatro español no solía colocarse en boca femenina: ¡Calderón arriesga!

Y, en tercer lugar, el efecto que Dinarda causa en Albano al aparecer ante él vestida de hombre es confusión, sorpresa y un despertar del antiguo enamoramiento, mientras que Rosaura opera en Segismundo una transformación completa, gracias a la visión platónica de la belleza y a su poder civilizador. Porque esta es la relación que importa: la amorosa es un tributo a la escena, un recurso de cara al público... Nunca el central en la concepción del dramaturgo.

\section{El vestido como signo: moda y maquillaje en el siglo $X X$}

La moda (vestido, maquillaje, look) ¿puede considerarse como un disfraz que se utiliza para realzar la personalidad femenina? ¿O como herramienta para encubrirla y multiplicarla, desvelando una mujer polifacética? ¿Una máscara, en el sentido etimológico del término? Porque en el teatro griego máscara significa persona y el cambio de máscara conlleva un salto cualitativo: cambiar de identidad.

Preguntas que chocan con planteamientos femeninos al estilo de Paul Poiret, quien en 1913 declaraba en la revista Vogue. "Vestir a una mujer no es cubrirla con ornamentos, es subrayar las cualidades de su cuerpo, hacerlas notar y recalcarlas. Es revelar lo natural acentuando la gracia". Una postura de un personaje revolucionario en esa historia de la moda que provocó asombro en las parisinas carreras de Longchamps por su colección de mujeres envueltas en túnicas, kimonos y turbantes... y a partir de ahí supo montar auténticas operaciones de marketing para vender sus diseños.

Su planteamiento está en la línea de lo que Diane Crane (2012) ha denominado "la moda como decoración corporal”, una forma de cultura material que tiene su lenguaje, en el que los estilos funcionan como significantes.

Pero ¿qué capacidad de maniobra, tendente a la expresión de su personalidad tienen esas mujeres manejadas como muñecas? Porque las mujeres del siglo XX, al menos de su segunda mitad, parecen haber heredado la hondura psicológica y filosófica de la Rosaura calderoniana. La mujer se siente femenina y masculina a la vez, capaz de trabajar fuera del hogar, tomar decisiones y construir la sociedad. Algo que 
la mujer decimonónica había comenzado a plantearse (las sufragistas) y que el cine lleva a la pantalla en La costilla de Adán (1949), de George Cukor, ensanchando los habituales estereotipos decimonónicos del ángel del hogar. Ya no necesita un disfraz para ejercer su papel de ciudadana con derechos y plena integración en la vida social a través de su trabajo; pero se apoya en una moda que ha cambiado y lo hará a partir de ahora, en función de sus necesidades. Dos guerras mundiales, el crack del 29 y las sucesivas crisis del siglo XX son más que suficientes para replantear trabajo y liberación femenina. Y los primeros modistos, desde que Worth abre en París (1857) su casa de costura e institucionaliza la figura del diseñador profesional, tendrán en cuenta el nuevo tipo femenino: Jeanne Lanvin en el faubourg St Honoré, o Madeleine Vionnet en la Rue Rivoli... incluso el elegante y conservador Edward Molyneux, quien diseña para la alta sociedad, financiará escuelas para trabajadores en el campo de la alta costura (Mir Balmaseda, 1995).

Desde el punto de vista femenino y como receptora de los dictados de la moda comienza una historia de liberación, pero también de seducción, porque la mujer juega con la doble cara (masculino/femenina) de la Rosaura calderoniana, conquista y se deja conquistar. Eso fue así desde que la Inglaterra de mitad del XIX inventó la máquina de coser y comenzó la producción de las telas en serie, cambio revolucionario donde los hubo. Ya Simmel, en su Filosofía de la moda conjeturó la mayor afinidad de la mujer con la moda porque carecía de otros ámbitos públicos en que verterse. $Y$ la historia parece haberle dado la razón: el furor del orientalismo a fines del XIX siglo, lo español en el París de Eugenia de Montijo, el deporte en el futurismo, la máscara indígena (vestidos, collares) en Frida Khalo...no harían sino corroborarlo.

Al otro lado del Atlántico y en la era del jazz, la flapper cuyo modelo literario fijó Fitzgerald en la novela A este lado del paraíso (1920) "encarna a la joven estadounidense moderna, soltera, sofisticada, amante de la diversión y liberada de las convenciones del comportamiento femenino establecidas por las generaciones anteriores" (Echart, 2005: 30). No es lo que se conoce como una feminista; pero a tono con los tiempos parece haber tomado las riendas de su destino creando para sí una nueva ¿máscara? ¿imagen? que "convirtió en rasgos distintivos el cuidado que prestaba a su apariencia pública (ropas cortas y reveladoras, joyas, cosméticos, perfumes, cigarrillos, etc) y la incorporación a lugares públicos de entretenimiento como podían ser los clubs de baile o los parques recreativos" (Echart, 2005: 30).

El boom de las revistas (Vogue, Femina, Chic Parisien...) con destinatario femenino permitió crearse a la mujer toda una fantasía visual de liberación. Su precio, accesible para la clase media, genera un imaginario muy alejado de su mundo real y en el que se refugia para compensar las insatisfacciones cotidianas. Se deja envolver por el glamour de la élite... aunque el propio concepto de élite haya ido desplazándose en el cuerpo social. Ya no son las cosmopolitas millonarias o aristócratas francesas e inglesas de los años locos parisinos, que viajan por todo el mundo y recalan en las carreras de caballos, los balnearios de Deauville, los casinos europeos o las playas del Mediterráneo. Ahora el mundo de las celebridades, (cantantes, presentadoras, artistas...) ocupa el primer lugar.

En la misma línea, la fotografía y el cine impulsaron la máscara del glamour, algo muy visible en la screwball comedy de Hollywood de los años 30 y 40, cuyas protagonistas con Catherine Hepbrun a la cabeza son las herederas de la flapper. Se trata de comedias que contagian " la exuberancia vital de unas parejas románticas genuinas y modernas, que dan prioridad en sus relaciones a valores como la diversión, la libertad y la igualdad" (Echart, 2005: 15). Esas películas necesitaron de los modistos 
europeos, que cruzan el Atlántico para vestir a las divas: un caso emblemático, el de Arien y Howard Greer con Greta Garbo en Matahari. En consecuencia, se crean iconos que las mujeres imitan masivamente. Porque la burguesía se deja fascinar por aristócratas y artistas.

Ilustración 2: Coco Chanel en su atelier de la Rue Cambon.

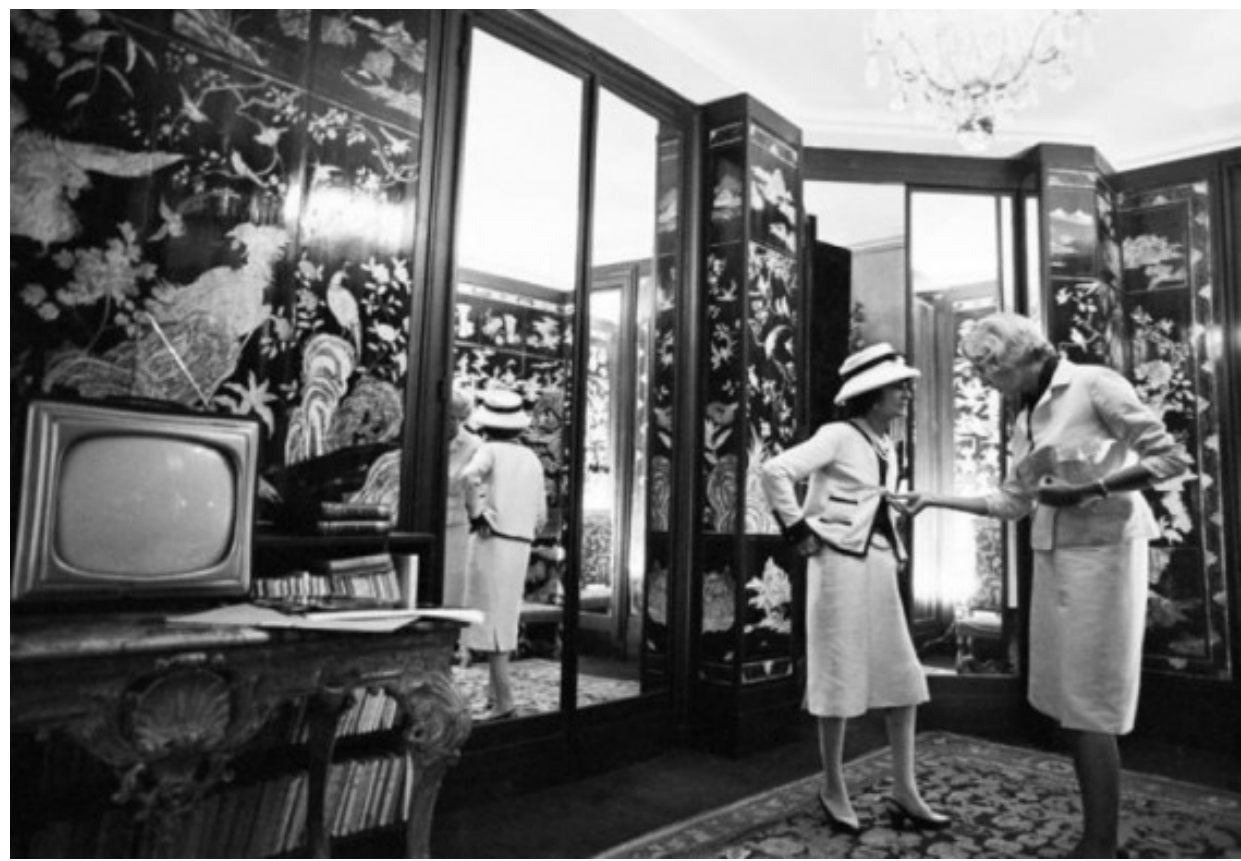

Fuente: http://www.cpp-luxury.com/chanel-launches-innovative-digital-campaign-to-reveal-theinsider-story-of-the-house/

En resumen, la historia de la moda dice mucho de la mujer: de los corsés decimonónicos al prêt-a-porter y la calculada informalidad de la mujer actual, pasando por la moda a lo garçonne de los años veinte, o la sencillez de Coco Chanel (traje sastre, el pequeño e insustituible traje negro, las perlas falsas y vistosas...). Por no hablar de la moda extravagante, vanguardista y lúdica de Schiaparelli, donde cada mujer parece un cuadro cubista (o se esconde bajo ese disfraz). O la elegancia de los Dior y Balenciaga que siguen resaltando atributos femeninos en las mujeres que pueden permitírselo. Y que siguen comprando a sus discípulos Givenchy, Courreges, Ungaro... Este es un mundo de modistos en que a la mujer le costó introducirse como agente creador de moda. Lo hizo desde abajo, casi como pidiendo perdón o colándose en los intersticios, como costurera de su hija y amigas (en el caso de Lanvin), o diseñadora de sombreros a base de remodelar los baratos de los almacenes: Coco Chanel. Con razón o sin ella, la liberación femenina en el siglo XX y desde la moda está unida a este nombre, llevado a la pantalla sin demasiado acierto por Anne Fontaine (2009).

Hoy la moda (como sucesión de disfraces o máscaras divertidas para la mujer) se ha convertido en el imperio de lo efímero, debido al incesante consumo y a pesar de las crisis. Sobre ello, Gilles Lipovetsky ha escrito páginas inolvidables en su libro homónimo (1990). El cine sigue imponiendo modelos (no hay sino recordar la moda colonial que siguió a Memorias de África (1985), de Sidney Pollack, donde Robert 
Redford y Meryl Streep impusieron el estilo safari colonial. La crisis aceleró la recuperación de lo vintage y triunfaron los armarios de las abuelitas y la ropa de segunda mano (Rhodes, 2008). Pierre Cardin presentó en 1959 la primera colección prêt-àporter de Printemps, lo que parecía el derrumbamiento de la alta costura. Pero sobre todo y como tendencia más general, subyacente a estilos concretos, se ha impuesto la exaltación de la juventud: si tradicionalmente las hijas les robaban tacones y barras de labios a sus madres; ahora las madres imitan a las hijas en su estilo informal y desenfadado. Por debajo el miedo a envejecer, al tempus fugit en una civilización cada vez más prágmatica que ama el carpe diem. La moda se mueve entre los parámetros de asimilación y distinción, como diagnosticaron sus primeros estudiosos (Simmel, Entwistle, o Bordieu, si bien este último en su teoría del gusto insiste más en la moda como lucha simbólica por parte de la clase alta, para mantener el estatus; y como producto de la emulación, por los de abajo): ninguna mujer quiere estar "fuera de la foto" y se leen los suplementos, se siguen los desfiles de las pasarelas con interés inusitado para, en un segundo momento marcar las distancias, conseguir un estilo propio, resaltar la personalidad, ser auténtica. En el fondo "tener estilo" es algo indefinible, que se resuelve en la tensión entre ambos polos (González, 2012).

La moda como disfraz, ¿liberación o nueva cárcel femenina? Porque la moda como sistema empresarial impone férreos códigos: "lo que se lleva". La pantalla también certifica, esta vez con acierto, cómo la mujer impone la dictadura de la moda desde revistas como Vogue. Me refiero a la exitosa película El diablo se viste de Prada (2006), de Frankel, donde una estupenda Meryl Streep encarna a la también excepcional redactora de esa revista, Anna Wintour. Hay que optar, como lo hace la joven periodista del film. Y es que, como le explica su madre a Fátima, la protagonista de la novela de Mernissi, Sueños en el umbral , "la ropa dice mucho de los propósitos de una mujer (...). Si piensas ser moderna, exprésalo con tu atuendo, de lo contrario te encerrarán en el harén. Los caftanes pueden ser de una belleza incomparable; pero el atuendo occidental representa el trabajo retribuido" (Mernissi, 1995: 103104). Asunto que nos llevaría muy lejos, a evaluar cuestiones dolorosas que también el cine ha reflejado en profundidad.

¿Y qué ocurre con la imagen de la mujer en internet? La red ha acercado la moda y la belleza al universo femenino de comienzos de siglo $\mathrm{XXI}$, un espacio aún por explorar donde la mujer sobrevive, superada ya la resaca del sueño de Superwoman que se convirtió en pesadilla a finales de siglo $\mathrm{XX}$. El maquillaje posee una fluidez que nunca tendrá el vestido, y como tal es signo y arma, digno heredero de la moda y verdadero artífice del disfraz femenino en nuestra época. Según König (La moda en el proceso de civilización, 2002) la cosmética se pierde en el origen de los tiempos, siempre unida al estatus. Y más modernamente, a la higiene y la medicina. Sin olvidar su carácter simbólico, muy ligado a la atracción mutua de los sexos.

De igual modo, el maquillaje aúna la doble vertiente de la que habla este artículo desde sus primeras líneas: permite a la mujer ser Dinarda y Rosaura al mismo tiempo. Desde el "diviértete... es sólo maquillaje" propugnado por François Nars se puede ascender hacia una visión más filosófica, en la cual una mujer podría construir identidades superpuestas y ahondar en su propia esencia por medio de un simple gesto: el de "pintarse los labios".

El acto de maquillarse hoy en día resulta tan revelador como pintar un cuadro con la yema de los dedos, y constituye la verdadera máscara de un tiempo en el que las mujeres no poseen quizás fortuna para construir su personalidad por medio de fastuosos vestidos: el llamado "efecto lipstick" determina que en tiempos de crisis, sube 
la venta de maquillaje a medida que se ralentiza y estanca el comercio de alta costura. En esta tesitura, el maquillaje habla, revela códigos ocultos y sobre todo permite a la mujer expresarse por medio de un lenguaje de color. Un colorido se adapta a la caída de las hojas en los parques o a las piruetas que se le ocurren a una señora como Bobbi Brown.

En efecto, este colorido cambiante recrea múltiples caras de una sola moneda: hoy en día existe el gloss efecto piruleta, el efecto boca mordida, el sfumatto y la imperfecta perfección. El maquillaje puede tratarse por capas y cada mujer puede lograr un acabado distinto en cada hora del día: trazo preciso, efecto de tizas en los párpados, rubor que esculpe o que rellena las mejillas... Todo se funde en la piel y se consiguen diversos acabados. Y el look natural es, por descontado, el que lleva más trabajo escondido.

Las revistas femeninas en papel (sobre las que se basan los estudios de Barthes) han sido durante la segunda mitad del siglo XX el canal de seducción por el cual llegaban a la mujer los nuevos códigos de disfraz (maquillaje, vestido) diseñados en gran medida por manos masculinas, pero esto ha evolucionado también. No sólo por la irrupción femenina en el diseño de la mano de grandes damas como Coco Chanel (ya un clásico) o Stella Mc Cartney (en la actualidad), sino porque en los tres primeros lustros del siglo XXI el canal se ha democratizado y diversificado: hoy en día cualquier mujer puede crear su propia máscara de color y darla a conocer al mundo a través de un blog.

\section{Conclusiones}

La moda, bien como fenómeno que arranca de la Antigüedad (König) o nace con la modernidad (Lipovetsky) es siempre un fenómeno total que va más allá del vestido y cuyo carácter expresivo está unido a códigos intocables marcados por la comunidad. Algo que recuerda Barthes al hablar del lenguaje de la moda y establecer toda una distinción entre un hecho de vestuario y otro de indumentaria. Sociólogos como Squiacciarino han titulado su libro "El vestido habla" (1990). Y es verdad: dice mucho de la identidad de quien lo adopta. Por otra parte, si la dialéctica imitación/ diferenciación rigió la moda (Simmel, Bordieu...) es porque existe una "Psicología del vestido" (Flügel) en que éste es símbolo del sexo, la ocupación y la posición social. Hoy esta dialéctica no funciona verticalmente como lo hiciera durante siglos, en que la clase alta aristocratizante era el modelo a imitar por la burguesía arribista. Como ha recordado Baudrillard en La sociedad de consumo. Sus mitos, sus estructuras (2009), la moda es un fenómeno que vertebra la sociedad de consumo, un fenómeno global que afecta a política, moral, sexualidad. Y que tiene una lógica fetichista; la ideología del consumo, el cuidado del cuerpo, el imperativo erótico (no necesariamente en este orden). "A la era sublime-artística del lujo le sucede su momento hiperrealista y financiero, en el que creación y búsqueda de alta rentabilidad se han vuelto inseparables" -dice Lipovetsky en El lujo eterno (2004: 53)-. "Hoy no queremos suscitar tanto la admiración social como seducir y estar cómodos, no tanto expresar una posición social como manifestar un gusto estético, y no tanto significar una posición de clase como parecer jóvenes y desenvueltos". Son sus palabras en El imperio de lo efímero (1990:165).

El objetivo general de este artículo era exponer de manera breve la idea de que el vestido fue signo de identidad femenina, pero también utilizado como disfraz por ciertos personajes femeninos de las comedias y tragedias del siglo XVII español, 
un arma para conseguir ampliar sus derechos. Vestido y maquillaje cumplen ambas funciones en el siglo XXI.

Uno de los objetivos específicos (eje troncal del trabajo) era analizar pormenorizadamente la función que ejerce el disfraz en el personaje de Rosaura, de La vida es sueño de Calderón de la Barca, y en Dinarda, de El anzuelo de Fenisa de Lope de Vega.

¿Han cambiado tanto los códigos a lo largo de estos siglos? ¿Qué es lo que ha mutado y lo que permanece igual por detrás de las máscaras? Dinarda y Rosaura como personajes femeninos tuvieron que ocultar su ropa, su feminidad. La mujer del siglo $\mathrm{XXI}$, tras un breve periplo en el cual parece que debía vestir como un ejecutivo para sobrevivir en un mundo de hombres, afirma su feminidad por medio del maquillaje: de nuevo, el disfraz como signo.

Y ese emblema, ¿es engaño o ficción? El maquillaje se afirma como creador y recreador de la personalidad cambiante de una mujer: ejecutiva triunfadora, enamorada, sufrida trabajadora, compañera, madre o amiga. Cada situación posee su propio código y a la vez constituye una puerta a la libertad de ser otra mujer distinta. Tal vez ninguno de esos dos personajes áureos, Dinarda y Rosaura, hubiera necesitado un disfraz masculino si corrieran sus aventuras en torno al año 2000: con un simple clic de barra de labios y otro clic de "ratón" les habría bastado para divertirse o para reparar su honor reteniendo a su lado a un galán olvidadizo. Maquillaje y teatro tienen un mismo denominador común: ambos visten mediante tramoyas de trampa y cartón los verdaderos sueños de un determinado público.

\section{Referencias bibliográficas}

Baudrillard, Jean 2009). La sociedad de consumo. Sus mitos. Sus estructuras. Madrid: Siglo XXI.

Bordieu, Pierre (2006). La distinción. Criterio y bases sociales del gusto. Madrid: Taurus.

Bravo Villasante, Carmen (1976). La mujer vestida de hombre en el teatro español (siglos XVI-XVII). Madrid: Sociedad General española de Librería.

Caballé, Anna (2013). El feminismo en España. La lenta conquista de un derecho. Madrid: Cátedra.

Calderón de la Barca, Pedro (1994). La vida es sueño. Ed. José María Ruano de la Haza. Madrid: Castalia.

Calderón de la Barca, Pedro (1997). La vida es sueño. Ed. Ciriaco Morón Arroyo. Madrid: Cátedra.

Codina, N. Merreros, Montserrat (eds.) (2004). Mirando la moda: once reflexiones. Madrid: Ediciones Internacionales Universitarias.

Crane, Diana (2012) Introducción a Identities through fashion. A multidisciplinary approach. Eds. Ana Marta González y Laura Bobone. London/New York: Berg.

De la Puente Herrera, Inmaculada (2011). El imperio de la moda. Madrid: Arcopress.

Eco, Umberto (2012). Arte y belleza en la estética medieval. Barcelona: De Bolsillo.

Echart, Pablo (2005). La comedia romántica del Hollywood de los años 30 y 40. Madrid: Cátedra. 
Entwistle, Joanne (2002). El cuerpo y la moda. Una visión sociológica. Barcelona: Paidós.

Escalonilla, Rosa Ana (2004). La dramaturgia del disfraz en Calderón. Pamplona: Eunsa.

Figueras, Josefina (ed.) (2009). Moda y valores. El desafío de lo nuevo. Madrid: Ediciones Internacionales Universitarias.

-(2014). Moda y estilos de vida: el poder de la novedad. Madrid: Ediciones Internacionales Universitarias.

Flügel, J. C. (1964). Psicología del vestido. Paidís: Buenos Aires.

Gavarrón, Lola (1989). La mística de la moda. Barcelona: Anagrama.

Gendrau Massaloux, Michélle (1983). "Rosaura en La vida es sueño: significado de una dualidad". Calderón, Actas del Congreso internacional, Madrid 8-13 junio 1981. Madrid: CSIC, II, 1039-1048.

González, Ana Marta y Laura Bobone (eds.) (2012). Identities through fashion. A multidisciplinary approach. London/New York: Berg.

Köhig, René (2009). La moda en el proceso de la civilización. Valencia: Engloba.

Lipovetsky, Gilles (1990). El imperio de lo efímero. Barcelona: Anagrama.

-y Roux, Elyette (2004). El lujo eterno. Barcelona: Anagrama.

Lurie, Alison (1994). El lenguaje de la moda. Barcelona: Paidós.

Mattalía, Sonia (2003). Máscaras suele vestir. Pasión y revuelta: Escrituras de mujeres en América Latina. Madrid/Frankfurt: Iberoamericana/Vervuert.

Mernissi, Fátima (1995). Sueños en el umbral. Memorias de una niña del harén. Madrid: Mario Muchnik.

Mir Balmaceda, $\mathrm{M}^{a}$ José (1995). La moda femenina en el París de las entreguerras. Las diseñadoras Coco Chanel y Elsa Schiaparelli. Madrid: EIUNSA.

Parker, Alexander Augustin (1991). La imaginación y el arte de Calderón. Madrid: Cátedra.

Rubio Liniers, $\mathrm{M}^{a}$ Carmen (2003). "La imagen de la mujer en Internet: de los estereotipos tradicionales al ciberfeminismo", en Imaginando a la mujer. Feminismos 2. P. Amador Carretero y M. Moreno editores. Alicante: Centro de Estudios sobre la Mujer de la Universidad de Alicante, Dic, 167-182.

Rubio Merino, Pedro (ed.) (1995). La monja alférez Doña catalina de Erauso. Dos manuscritos autobiográficos inéditos. Sevilla: Ediciones del cabildo metropolitano de la Catedral de Sevilla.

Simmel, Geor (1924). Filosofía de la coquetería, filosofía de la moda. Lo masculino y lo femenino; $y$ otros ensayos. Madrid: Revista de Occidente.

Soley-Beltrán, Patricia (2015). ¡Divinas! Modelos, poder y mentiras. Barcelona: Anagrama.

Squicciarino, Nicola. El vestido habla. Madrid: Cátedra.

Torras Frances, Meri (2003). Soy como consiga que me imaginéis: la construcción de la subjetividad en las autobiografías epistolares de Gertrudis Gómez de Avellaneda y Sor Juana Inés de la Cruz. Cádiz: Servicio de Publicaciones de la Universidad de Cádiz. 
Valbuena Prat, Ángel, y Wardropper, Bruce W. (1983). "Capa y espada: entre la comedia y la tragedia”, en Francisco Rico (ed.). Historia y Crítica de la literatura española. Barcelona: Crítica, III, 769-776.

Vega, Lope de (1973). Arte nuevo de hacer comedias. La discreta enamorada. Madrid: Espasa-Calpe.

Vega, Lope de (1998). El anzuelo de Fenisa, en Comedias XV. Ed. Domingo Ynduraín. Madrid: Fundación José Antonio de Castro.

Whitby, William (1976). "El papel de Rosaura en la estructura de La vida es sueño". Calderón y la crítica: Historia y antología. Eds. Manuel Durán y Roberto González Echevarría. Madrid: Gredos, II, 629-646.

\section{Referencias bibliográficas}

Bravo Villasante, Carmen (1976). La mujer vestida de hombre en el teatro español (siglos XVI-XVII). Madrid: Sociedad General española de Librería.

Caballé, Anna (2013). El feminismo en España. La lenta conquista de un derecho. Madrid: Cátedra.

Calderón de la Barca, Pedro (1994). La vida es sueño. Ed. José María Ruano de la Haza. Madrid: Castalia.

Calderón de la Barca, Pedro (1997). La vida es sueño. Ed. Ciriaco Morón Arroyo. Madrid: Cátedra.

Crane, Diana (2012) Introducción a Identities through fashion. A multidisciplinary approach. Eds. Ana Marta González y Laura Bobone. London/New York: Berg.

Echart, Pablo (2005). La comedia romántica del Hollywood de los años 30 y 40. Madrid: Cátedra.

Escalonilla, Rosa Ana (2004). La dramaturgia del disfraz en Calderón. Pamplona: Eunsa.

Gendrau Massaloux, Michélle (1983). "Rosaura en La vida es sueño: significado de una dualidad". Calderón, Actas del Congreso internacional, Madrid 8-13 junio 1981. Madrid: CSIC, II, 1039-1048.

González, Ana Marta y Laura Bobone (eds.) (2012). Identities through fashion. A multidisciplinary approach. London/New York: Berg.

Hart, Avril y Susan North (2009). La moda de los siglos XVII y XVIII en detalle. Fotografías de Richard Davis. Dibujos de Leonie Davis. Barcelona: Gustavo Gili.

Lurie, Alison (1994). El lenguaje de la moda. Una interpretación de la forma de vestir. Barcelona: Paidós Ibérica.

Mattalía, Sonia (2003). Máscaras suele vestir. Pasión y revuelta: Escrituras de mujeres en América Latina. Madrid/Frankfurt: Iberoamericana/Vervuert.

Mernissi, Fátima (1995). Sueños en el umbral. Memorias de una niña del harén. Madrid: Mario Muchnik.

Mir Balmaceda, Ma José (1995). La moda femenina en el París de las entreguerras. Las diseñadoras Coco Chanel y Elsa Schiaparelli. Madrid: EIUNSA.

Parker, Alexander Augustin (1991). La imaginación y el arte de Calderón. Madrid: Cátedra. 
Puente Herrera, Inmaculada de la (2011). El imperio de la moda. Madrid: Arcopress.

Rivière, M. (2014). Diccionario de la moda. Los estilos del siglo XX. Ilustraciones de Antonio Miró. Barcelona: De Bolsillo (e. o. 1996).

Rubio Liniers, $\mathrm{M}^{a}$ Carmen (2003). "La imagen de la mujer en Internet: de los estereotipos tradicionales al ciberfeminismo", en Imaginando a la mujer. Feminismos 2. P. Amador Carretero y M. Moreno editores. Alicante: Centro de Estudios sobre la Mujer de la Universidad de Alicante, Dic, 167-182.

Rubio Merino, Pedro (ed.) (1995). La monja alférez Doña catalina de Erauso. Dos manuscritos autobiográficos inéditos. Sevilla: Ediciones del cabildo metropolitano de la Catedral de Sevilla.

Solange Solteras, Ma Concepción (2009). La moda en la sociedad aragonesa del XVI. Zaragoza: Institución Fernando el católico.

Torras Frances, Meri (2003). Soy como consiga que me imaginéis: la construcción de la subjetividad en las autobiografías epistolares de Gertrudis Gómez de Avellaneda y Sor Juana Inés de la Cruz. Cádiz: Servicio de Publicaciones de la Universidad de Cádiz.

Valbuena Prat, Ángel, y Wardropper, Bruce W. (1983). "Capa y espada: entre la comedia y la tragedia", en Francisco Rico (ed.). Historia y Crítica de la literatura española. Barcelona: Crítica, III, 769-776.

Vega, Lope de (1973). Arte nuevo de hacer comedias. La discreta enamorada. Madrid: Espasa-Calpe.

Vega, Lope de (1998). El anzuelo de Fenisa, en Comedias XV. Ed. Domingo Ynduraín. Madrid: Fundación José Antonio de Castro.

Whitby, William (1976). "El papel de Rosaura en la estructura de La vida es sueño". Calderón y la crítica: Historia y antología. Eds. Manuel Durán y Roberto González Echevarría. Madrid: Gredos, II, 629-646. 